\title{
Healthcare-Associated Infections in Pediatric and Neonatal Intensive Care Units: Impact of Underlying Risk Factors and Antimicrobial Resistance on 30-Day Case-Fatality in Italy and Brazil
}

\author{
Laura Folgori, MD; ${ }^{1,2}$ Paola Bernaschi, MSc; ${ }^{3}$ Simone Piga, MSc; ${ }^{4}$ Michaela Carletti, MSc; ${ }^{3}$ Filippe Pirrone Cunha, BSc; ${ }^{5}$ \\ Paulo Henrique Rodriguez Lara, BSc; ${ }^{5}$ Nicholas Cafieiro de Castro Peixoto, BSc; ${ }^{5}$ Bárbara Gomes Alves Guimarães, BSc; ${ }^{5}$ \\ Mike Sharland, MD; ${ }^{2}$ André Ricardo Araujo da Silva, MD; ${ }^{5,6}$ Marta Ciofi degli Atti, $\mathrm{MD}^{4}$
}

овјестіves. To describe trends in the epidemiology of healthcare-associated Infections (HAIs) in pediatric/neonatal intensive care units (ICUs) and to evaluate risk factors and impact of multidrug resistance in children admitted to ICUs.

DESIGN. Multicenter, retrospective, cohort study with a nested case-control study conducted from January 1, 2010, through December 31, 2014.

SETTING. Three tertiary care pediatric hospitals in Italy and Brazil with a total of 103 ICU beds.

PATIENTS. Inclusion criteria were admission to ICU during the study period, age at onset less than 18 years, and microbiologically confirmed HAI.

RESULTS. A total of 538 HAIs in 454 children were included; $93.3 \%$ of patients had comorbidities. Bloodstream infections were the leading pattern (45.4\%). The cumulative incidence of HAI was 3.6/100 ICU admissions and the crude 30-day fatality rate was 5.7/1,000 admissions. The most frequently isolated pathogens were Enterobacteriaceae, followed by Pseudomonas aeruginosa and Staphylococcus aureus. Forty-four percent of isolates were multidrug-resistant (MDR). Two multivariate logistic regressions were performed. Factors independently associated with an MDR-HAI were country, previous antibiotics, transplantation, major surgery, and colonization by an MDR strain. Factors independently associated with 30-day case fatality were country, previous transplantation, fungal infection, bloodstream infection, lower respiratory tract infection, and infection caused by MDR strains.

CONCLUSIONs. Infection control and prevention can limit the spread of MDR strains and improve outcomes. Targeted surveillance programs collecting neonatal and pediatric HAI/bloodstream infection data and outcomes would allow global benchmarking. The next step is to identify methods to monitor key HAIs and integrate these into affordable intervention programs.

Infect Control Hosp Epidemiol 2016;37:1302-1309

Healthcare-associated infections (HAIs) are one of the most frequent adverse events affecting children admitted to intensive care units (ICUs). ${ }^{1,2}$ Exposure to invasive devices and procedures, immune suppression, and underlying conditions are considered as main determinants of patients' increased susceptibility. ${ }^{3,4}$ The impact of multidrug-resistant (MDR) organisms in pediatrics is increasing globally. ${ }^{5-7}$ It is assumed that infections caused by MDR bacteria will have a worse prognosis because of the delay in the administration of appropriate therapy. However, it is difficult to estimate the clinical impact of MDR-HAI in children.
Previous literature has shown conflicting results about the impact of different underlying risk factors on the clinical outcome of patients with HAI admitted to ICUs. There is no clear independent correlation between antimicrobial resistance and patients' mortality. ${ }^{8-11}$

Clarifying the relationship between patient risk factors and pediatric HAI mortality could allow improved targeting of interventions on the patients most at risk of adverse outcome. The aims of this study were to describe trends in the epidemiology of HAIs in Italian and Brazilian pediatric ICUs over a 5-year period and to evaluate patient risk factors and the clinical impact of MDR-HAI in children admitted to ICUs.

Affiliations: 1. University Department of Pediatrics, Bambino Gesù Children's Hospital, Rome, Italy; 2. Paediatric Infectious Disease Research Group, Institute for Infection and Immunity, St George's University of London, London, United Kingdom; 3. Unit of Microbiology, Bambino Gesù Children's Hospital, Rome, Italy; 4. Unit of Clinical Epidemiology, Bambino Gesù Children’s Hospital, Rome, Italy; 5. Faculty of Medicine, Federal Fluminense University, Niterói, Brazil; 6. Infection Control Committee, Prontobaby Hospital da Criança, Rio de Janeiro, Brazil. A.R.A.d.S. and M.C.d.A. contributed equally to this article.

Received April 6, 2016; accepted July 15, 2016; electronically published August 11, 2016 (c) 2016 by The Society for Healthcare Epidemiology of America. All rights reserved. 0899-823X/2016/3711-0005. DOI: 10.1017/ice.2016.185 


\section{METHODS}

\section{Study Design and Setting}

We conducted a multicenter, retrospective, cohort study with a nested case-control study in 1 pediatric hospital in Italy and 2 in Brazil. These countries were chosen because of the high rates of antimicrobial resistance identified. The Bambino Gesù Children's Hospital (Rome, Italy) is a 607-bed pediatric tertiary care center with 5 ICUs: 1 neonatal, 3 pediatric, and 1 cardiac (47 ICU beds). The Prontobaby Hospital da Criança (Rio de Janeiro, Brazil) is a 135-bed private service including neonatal ICU and pediatric ICU (45 ICU beds). The Centro Pediátrico da Lagoa (Rio de Janeiro, Brazil) is a 39-bed private service including an 11-bed pediatric ICU.

The study was conducted from January 1, 2010, through December 31, 2014. During this period, ongoing prospective surveillance of HAIs was performed in all the participating ICUs. Patients with a microbiologically confirmed diagnosis of HAI were retrieved from this data source. Inclusion criteria were admission to ICU during the study period, age at onset less than 18 years, and diagnosis of microbiologically confirmed HAI. Polymicrobial infections were included if criteria for HAI were fulfilled. Episodes with a positive isolate from the same patient for the same pathogen within 4 weeks of the first one were excluded.

\section{Definitions}

The study was conducted using Centers for Disease Control and Prevention HAI case definitions, with only those infections presenting and identified more than 48 hours after admission to ICU considered as ICU-acquired and included. ${ }^{12}$

The multidrug resistance of the isolates was defined according to Magiorakos et al. ${ }^{13}$ Coagulase-negative staphylococci were considered as MDR if resistant to 3 or more different antibiotic classes, including oxacillin, aminoglycosides, trimethoprim-sulfamethoxazole, clindamycin, and quinolones. ${ }^{14}$ Isolates that did not meet MDR definition were classified as susceptible. Patients with polymicrobial infection with mixed MDR and non-MDR isolates were classified as MDR. Cases were defined as patients with HAI due to MDR isolates. Controls were defined as patients with HAIs caused by non-MDR.

\section{Microbiologic Methods}

In Italy, isolation and identification of microorganisms were made with accredited routine laboratory methods (Vitek 128 2, bioMérieux; or Phoenix, BD Diagnostics). The Clinical and Laboratory Standards Institute criteria were used for antibiotic susceptibility testing from 2010 to 2011 whereas from 2012 the European Committee on Antimicrobial Susceptibility Testing breakpoints have been introduced in the hospital's practice.

In Brazil, isolation of microbiological species was done by semiquantitative process (Auto-Scan 4; Siemens). Antibiotic susceptibility testing was performed by disk diffusion in accordance with Clinical and Laboratory Standards Institute recommendations until 2013 and with European Committee on Antimicrobial Susceptibility Testing from 2014.

Prior colonization with MDR strains was assessed by stool culture/rectal swab.

\section{Data Source and Statistical Analysis}

We considered the cohort of patients admitted to the ICU to estimate HAI cumulative incidence (HAI episodes/100 ICU admissions), rate of infections (HAI episodes/1,000 ICU-days), and mortality rate at 7 and 30 days after HAI onset (deaths among patients with at least $1 \mathrm{HAI}$ episode/1,000 ICU admissions). For all HAI episodes we collected information about possible risk factors, including demographic, clinical, and microbiologic variables from inpatient clinical and laboratory records. We then compared cases vs controls to evaluate determinants for acquisition of HAI due to MDR compared with non-MDR HAI. Predictors of 30-day HAI case fatality rate were estimated by comparing survivors vs nonsurvivors.

Categorical variables were summarized by absolute frequencies and percentages, and continuous variables by median and interquartile range. To determine statistical differences between groups, the $\chi^{2}$ test or Fisher exact test was used for categorical variables, whereas the $t$ test or Mann-Whitney test was used for continuous variables.

Two multivariate logistic regression models were developed to assess independent predictors of acquisition of MDR-HAI compared with non-MDR-HAI as well as 30-day HAI case fatality rate. Variables for which $P<.20$ in univariate analyses were included in the multivariate models. Final models were computed with a stepwise backward procedure (likelihood ratio test, $P<.05$ ).

All statistical analyses were performed using Stata, version 13 (StataCorp).

\section{Ethics}

The study was approved by the ethical committee of each institution with a waiver of informed consent.

\section{RESULTS}

\section{Demographic and Clinical Data}

During the study period 14,924 children were admitted to one of the ICUs for a total of 148,243 ICU-days. Overall, $538 \mathrm{HAI}$ episodes in 454 children, fulfilling the inclusion criteria, were identified and included in the analysis.

Characteristics of episodes of HAI are summarized in Table 1. Bloodstream infections (BSIs) were the leading pattern accounting for 244 episodes (45.4\%), followed by lower respiratory tract infections (LRTIs) with 149 (27.8\%) and urinary tract infections with 85 (15.8\%).

The median (interquartile range) age of patients at HAI onset was 7.8 (2.1-26.2) months; $93.3 \%$ of HAI cases affected children with comorbidities. The median (interquartile range) 
TABLE 1. Characteristics of Episodes of HAI Included in the Study

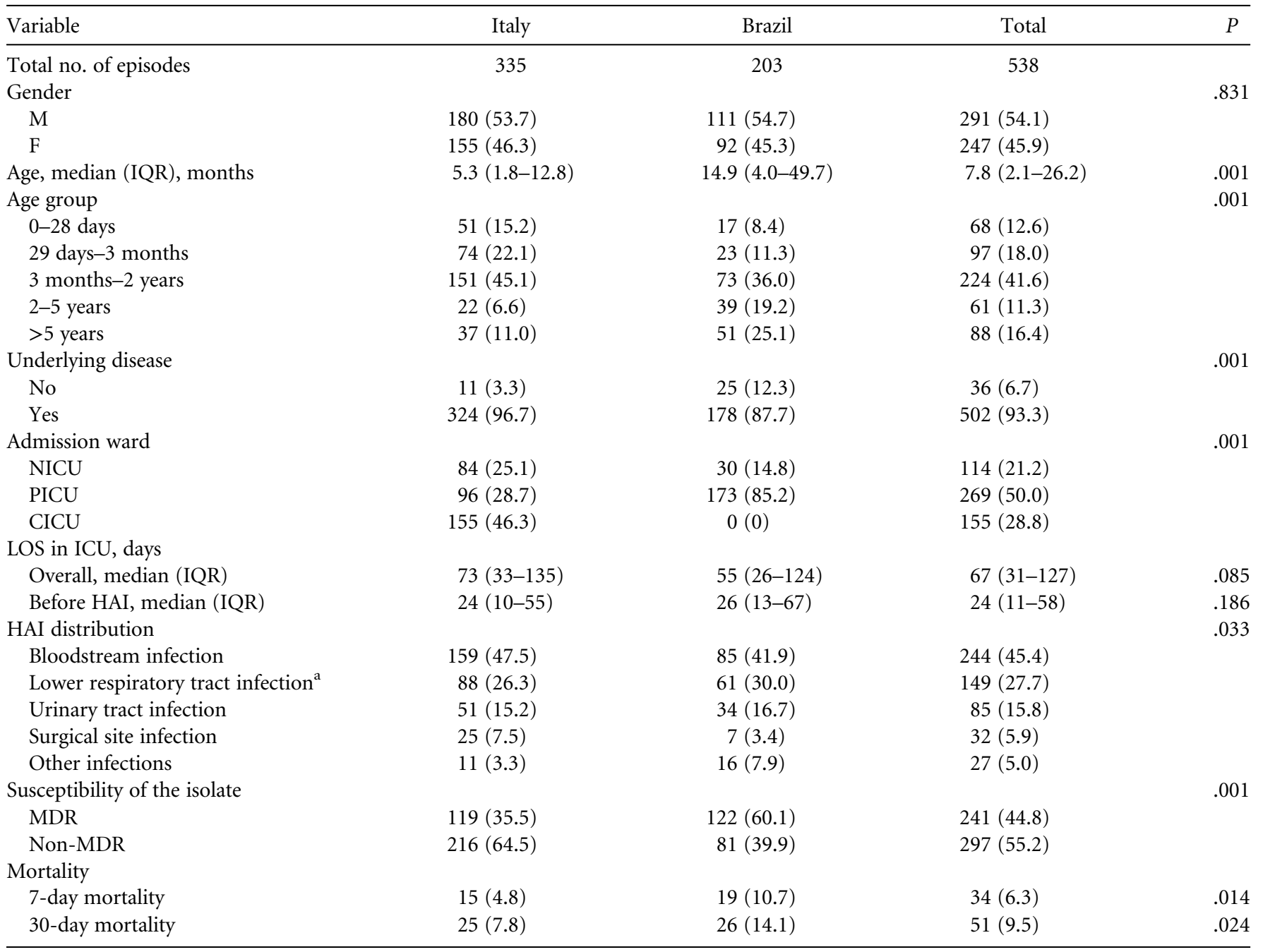

NOTE. Data are no. (\%) of episodes unless otherwise indicated. CICU, cardiac intensive care unit; HAI, healthcare-associated infection; ICU, intensive care unit; IQR, interquartile range; LOS, length of stay; MDR, multidrug-resistant; NICU, neonatal intensive care unit; PICU, pediatric intensive care unit.

${ }^{\mathrm{a}}$ Including pneumonia.

length of stay in ICU was 67 (31-127) days, whereas the median (interquartile range) time between ICU admission and onset of HAI was 24 (11-58) days.

Overall, $478(88.8 \%)$ of the 538 HAIs were diagnosed in patients with an invasive device in situ. In $443(82.3 \%)$ of the 538 HAIs, the device had been in place for more than 48 hours before the infection. Among 244 BSIs, 195 (79.9\%) involved children with a central venous catheter (CVC) in situ when diagnosed (179 [73.4\%] of these 244 for $>48$ hours). Also, $120(80.5 \%)$ of 149 LRTIs were in children mechanically ventilated (100 [67.1\%] of these 149 for $>48$ hours). Among 85 urinary tract infections, 38 were in children who had a urinary catheter (28 [32.9\%] of the 85 for $>48$ hours).

In $318(59.1 \%)$ of 538 episodes, children were already receiving antibiotics when diagnosed with a HAI (141 [44.3\%] were on 1 antibiotic, $130[40.9 \%]$ on 2 , and $47[14.8 \%]$ on 3$)$.
The cumulative incidence of HAI was 3.6/100 ICU admissions whereas the rate of infections was 3.6/1,000 ICU-days. No significant trends in HAI incidence and rate were identified over the 5-year period. The 7-day mortality rate was $2.3 / 1,000$ admissions and the 30-day mortality rate was $5.7 / 1,000$ admissions. The HAI case fatality rate at 30 days was $18.7 \%$ $(85 / 454)$.

\section{Microbiologic Data}

A total of 573 microorganisms were isolated (Table 2). Of these 573 microorganisms, 317 (55\%) were Gram-negative bacteria, $184(32 \%)$ were Gram-positive bacteria, and $40(7 \%)$ were fungi. The most frequently isolated pathogens were Enterobacteriaceae (30.9\%), followed by Pseudomonas aeruginosa (19.2\%) and Staphylococcus aureus (11.0\%). The percentage of 
TABLE 2. Distribution and Resistance of Isolates by Type of HAI

\begin{tabular}{|c|c|c|c|c|c|c|c|c|c|c|c|c|c|c|c|}
\hline \multirow{3}{*}{$\frac{\text { Pathogen }}{\text { Total isolates }}$} & \multirow{2}{*}{\multicolumn{3}{|c|}{$\begin{array}{c}\begin{array}{c}\text { Bloodstream } \\
\text { infection }\end{array} \\
252\end{array}$}} & \multirow{2}{*}{\multicolumn{3}{|c|}{$\begin{array}{c}\begin{array}{c}\text { Lower respiratory tract } \\
\text { infection }^{a}\end{array} \\
164\end{array}$}} & \multirow{2}{*}{\multicolumn{3}{|c|}{$\begin{array}{c}\begin{array}{c}\text { Urinary tract } \\
\text { infection }\end{array} \\
94\end{array}$}} & \multirow{2}{*}{\multicolumn{3}{|c|}{$\begin{array}{c}\begin{array}{c}\text { Surgical site } \\
\text { infection }\end{array} \\
35\end{array}$}} & \multirow{2}{*}{\multicolumn{3}{|c|}{$\frac{\text { Other }}{27}$}} \\
\hline & & & & & & & & & & & & & & & \\
\hline & $\mathrm{n}$ & n MDR & $\%$ & $\mathrm{n}$ & $\mathrm{n} M D R$ & $\%$ & $\mathrm{n}$ & $\mathrm{n}$ MDR & $\%$ & $\mathrm{n}$ & $\mathrm{n}$ MDR & $\%$ & $\mathrm{n}$ & $\mathrm{n}$ MDR & $\%$ \\
\hline Total Gram-positives & 110 & 52 & 47.3 & 31 & 19 & 61.3 & 13 & 3 & 23.1 & 16 & 9 & 56.3 & 14 & 9 & 64.3 \\
\hline Total Gram-negatives & 107 & 44 & 41.1 & 115 & 52 & 45.2 & 66 & 35 & 53 & 16 & 8 & 50 & 12 & 9 & 75 \\
\hline Klebsiella pneumoniae & 31 & 11 & 35.5 & 17 & 8 & 47.1 & 17 & 13 & 76.5 & 4 & 4 & 100 & 2 & 2 & 100 \\
\hline Escherichia coli & 10 & 3 & 30 & 9 & 3 & 33.3 & 18 & 8 & 44.4 & 1 & 0 & - & 1 & 1 & 100 \\
\hline Pseudomonas aeruginosa & 27 & 13 & 48.1 & 57 & 23 & 40.4 & 19 & 9 & 47.4 & 6 & 3 & 50 & 1 & 0 & - \\
\hline Serratia marcescens & 9 & 1 & 11.1 & 3 & 0 & - & 4 & 1 & 25 & 0 & - & - & 1 & 1 & 100 \\
\hline Stenotrophomonas maltophilia & 4 & 4 & 100 & 14 & 14 & 100 & 1 & 1 & 100 & 0 & - & - & 0 & - & - \\
\hline Other Gram-positives & 3 & 0 & - & 2 & 0 & - & 0 & - & - & 0 & - & - & 2 & 0 & - \\
\hline Other Gram-negatives ${ }^{b}$ & 13 & 5 & 38.5 & 12 & 6 & 50 & 7 & 2 & 28.6 & 3 & 0 & - & 1 & 0 & - \\
\hline
\end{tabular}

NOTE. CoNS, coagulase-negative staphylocci; HAI, healthcare-associated infection; MDR, multidrug-resistant.

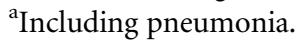

${ }^{\mathrm{b}}$ There was one missing case.

MDR isolates was $44 \%$. On the basis of the susceptibility profile, $79(45 \%)$ of the 175 Enterobacteriaceae were positive for extended-spectrum beta-lactamase. Culture-confirmed carbapenem resistance was reported in $3(2 \%)$ of the 175 Enterobacteriaceae, 46 (42\%) of 110 P. aeruginosa, and 6 of 10 Acinetobacter baumannii. Among Gram-positives, 35 (56\%) of $63 \mathrm{~S}$. aureus were methicillin-resistant whereas no vancomycin-resistant Enterococcus spp. were isolated. Seventysix coagulase-negative staphylococci were isolated, of which 47 (62\%) were classified as MDR. Overall, 40 cultures were positive for Candida spp., all of them fully sensitive.

\section{Determinants of HAI Due to MDR and 30-Day Case Fatality Rate}

Of a total of 538 episodes, 241 were due to MDR isolates and 297 to non-MDR isolates, with no statistically significant differences in cumulative incidence (1.61 episodes/100 ICU admissions vs 1.99 episodes/100 ICU admissions; $P=.995$ ). The 30-day case fatality rate was also similar in MDR-HAI episodes compared with non-MDR episodes (19.1\% vs $13.1 \%$; $P=.06)$.

In the univariate analysis, risk factors significantly associated with HAI caused by MDR isolates compared with non-MDR isolates were country (Brazil), antibiotic use in the month before HAI, minor surgery in the 6 months before HAI, and previous colonization by a MDR strain (Table 3 ).

In the multivariate analysis, factors independently associated with an MDR-HAI were country (Brazil), antibiotic use in the month before HAI, previous transplantation, major surgery in the 6 months before HAI, and previous colonization by an MDR strain (Table 3 ).

Risk factors associated with the 30-day case fatality rate are summarized in Table 4 . In the univariate analysis, factors significantly associated with the 30-day case fatality rate were country (Brazil), prematurity, type of HAI, and microorganism category. In the multivariate multilevel analysis, factors independently associated with the 30-day case fatality rate were previous transplantation, BSI, LRTI, infection caused by fungi compared with Gram-positive bacteria, and infection caused by an MDR strain. The $2-5$ years age group was a protective factor compared with the 0-28 days age group.

\section{DISCUSSION}

We reported a 5-year experience of microbiologically confirmed HAIs in 8 ICUs at 3 children's hospitals in Italy and Brazil. Our study involved nearly 15,000 patients admitted in 2010-2014, and data on 538 HAIs were included. This cohort was larger compared with previous studies published in pediatrics. We documented a HAI incidence of $3.6 \%$ and an infection rate of 3.6/1,000 ICU-days. Compared with previous reports, our rates were lower than expected, since the incidence of HAIs has been previously reported as between $7 \%$ and $12 \%$ in pediatric and between $15 \%$ and $20 \%$ in neonatal ICUs. ${ }^{4,6,15-18}$ The great majority of children in our cohort had an underlying disease $(93.3 \%)$, a proportion quite similar to previous data in pediatric ICUs. ${ }^{19}$

Consistent with previous studies, BSIs represented the leading cause of pediatric HAIs, followed by LRTIs and urinary 
TA B LE 3. Univariate and Multivariate Regression Analysis of the Impact of Cohort Characteristics on HAIs Caused by MDR Isolates

\begin{tabular}{|c|c|c|c|c|c|c|c|c|c|}
\hline Variable & $\begin{array}{c}\text { MDR } \\
(\mathrm{n}=241)\end{array}$ & $\begin{array}{l}\text { Non-MDR } \\
(\mathrm{n}=297)\end{array}$ & $P$ & Crude OR & $(95 \% \mathrm{CI})$ & $P$ & $\begin{array}{l}\text { Adj } \\
\text { OR }\end{array}$ & $(95 \% \mathrm{CI})$ & $P$ \\
\hline Country & & & .001 & & & & & & \\
\hline Italy & $119(35.5)$ & $216(64.5)$ & & 1 [Ref] & & & $1[$ Ref $]$ & & \\
\hline Brazil & $122(60.1)$ & $81(39.9)$ & & 2.73 & $(1.91-3.92)$ & .001 & 3.11 & $(1.86-5.20)$ & $<.001$ \\
\hline Age group & & & .070 & & & & N.I. & & \\
\hline $0-28$ days & $25(36.8)$ & $43(63.2)$ & & $1[$ Ref] & & & & & \\
\hline 29 days -3 months & $40(41.2)$ & $57(58.8)$ & & 1.21 & $(0.64-2.28)$ & .563 & & & \\
\hline 3 months -2 years & $95(42.4)$ & $129(57.6)$ & & 1.27 & $(0.72-2.22)$ & .408 & & & \\
\hline $2-5$ years & $35(57.4)$ & $26(42.6)$ & & 2.32 & $(1.14-4.70)$ & .020 & & & \\
\hline$>5$ years & $46(52.3)$ & $42(47.7)$ & & 1.88 & $(0.99-3.59)$ & .055 & & & \\
\hline Male gender & $136(46.7)$ & $155(53.3)$ & .326 & 1.19 & $(0.84-1.67)$ & .326 & & & \\
\hline Underlying conditions & & & .319 & & & & & & \\
\hline No & $19(52.8)$ & $17(47.2)$ & & 1 [Ref] & & & & & \\
\hline Yes & $222(44.2)$ & $280(55.8)$ & & 0.71 & $(0.36-1.40)$ & .321 & & & \\
\hline Risk category & & & .212 & & & & & & \\
\hline Surgery & $72(38.3)$ & $116(61.7)$ & & $1[$ Ref $]$ & & & $1[$ Ref $]$ & & \\
\hline Immunodeficiency & $6(40.0)$ & $9(60.0)$ & & 1.07 & $(0.37-3.14)$ & .896 & 1.51 & $(0.46-4.96)$ & .500 \\
\hline Transplantation & $8(66.7)$ & $4(33.3)$ & & 3.22 & $(0.94-11.09)$ & .063 & 4.17 & $(1.12-15.61)$ & .034 \\
\hline Cancer & $10(62.5)$ & $6(37.5)$ & & 2.69 & $(0.94-7.70)$ & .066 & 1.17 & $(0.37-3.66)$ & .790 \\
\hline Renal failure & $5(45.5)$ & $6(54.6)$ & & 1.34 & $(0.40-4.56)$ & 637 & 0.89 & $(0.22-3.63)$ & .874 \\
\hline Prematurity & $17(44.7)$ & $21(55.3)$ & & 1.30 & $(0.65-2.63)$ & .459 & 2.25 & $(0.96-5.31)$ & .063 \\
\hline Other & $102(46.4)$ & $118(53.6)$ & & 1.39 & $(0.94-2.07)$ & .101 & 1.41 & $(0.82-2.43)$ & .211 \\
\hline $\mathrm{AB}$ use in the month before HAI & & & .001 & & & & & & \\
\hline No & $20(27.8)$ & $52(72.2)$ & & $1[$ Ref] & & & 1 [Ref] & & \\
\hline Yes & $217(48.2)$ & $233(51.8)$ & & 2.42 & $(1.40-4.19)$ & .002 & 2.10 & $(1.14-3.88)$ & .017 \\
\hline \multicolumn{10}{|l|}{ Type of $A B$} \\
\hline Penicillin/ampicillin & $7(36.8)$ & $12(63.2)$ & .442 & 1.52 & $(0.52-4.40)$ & .443 & & & \\
\hline $\begin{array}{l}\text { Combination of penicillin, incl. beta- } \\
\text { lactamase inhibitor }\end{array}$ & $15(41.7)$ & $21(58.3)$ & .146 & 1.86 & $(0.80-4.30)$ & .148 & N.I. & & \\
\hline Cephalosporin 2nd & $23(32.9)$ & $47(67.1)$ & .510 & 1.30 & $(0.63-2.67)$ & .474 & & & \\
\hline Cephalosporin 3rd & $21(53.9)$ & $18(46.2)$ & .007 & 3.03 & $(1.34-6.84)$ & .008 & 1.85 & $(0.90-3.81)$ & .093 \\
\hline Carbapenem not combined with enzyme & $48(57.1)$ & $36(42.9)$ & .001 & 3.47 & $(1.77-6.79)$ & .001 & 1.60 & $(0.93-2.66)$ & .093 \\
\hline Combination of sulfonamized/trimethoprim & $2(40.0)$ & $3(60.0)$ & .620 & 1.73 & $(0.27-11.15)$ & .563 & & & \\
\hline Macrolide & $7(58.3)$ & $5(41.7)$ & .048 & 3.64 & $(1.03-12.81)$ & .044 & N.I. & & \\
\hline Aminoglycoside & $15(44.1)$ & $19(55.9)$ & .095 & 2.05 & $(0.88-4.81)$ & .098 & N.I. & & \\
\hline Quinolone & $24(50.0)$ & $24(50.0)$ & .023 & 2.60 & $(1.21-5.59)$ & .014 & N.I. & & \\
\hline Glycopeptide & $32(48.5)$ & $34(51.5)$ & .012 & 2.45 & $(1.21-4.96)$ & .013 & N.I. & & \\
\hline Surgery in the previous 6 months & & & .063 & & & & & & \\
\hline No & $91(43.5)$ & $118(56.5)$ & & 1 [Ref] & & & 1 [Ref] & & \\
\hline Minor & $40(58.0)$ & $29(42.0)$ & & 1.80 & $(1.04-3.13)$ & .036 & 1.81 & $(0.98-3.33)$ & .058 \\
\hline Major & $110(42.5)$ & $149(57.5)$ & & 0.97 & $(0.68-1.39)$ & .851 & 1.99 & $(1.10-3.58)$ & .022 \\
\hline Invasive devices & & & .833 & & & & & & \\
\hline No & $18(43.9)$ & $23(56.1)$ & & 1 [Ref] & & & & & \\
\hline Yes & $218(45.6)$ & $260(54.4)$ & & 1.01 & $(0.54-1.91)$ & .963 & & & \\
\hline Previous colonization by MDR & & & .001 & & & & & & \\
\hline No & $139(38.7)$ & $220(61.3)$ & & 1 [Ref] & & & 1 [Ref] & & \\
\hline Yes & $87(63.0)$ & $51(37.0)$ & & 2.70 & $(1.80-4.05)$ & .001 & 1.72 & $(1.08-2.76)$ & .023 \\
\hline
\end{tabular}

NOTE. Data are no. (\%) of isolates in that column unless otherwise indicated. AB, antibiotic; HAI, healthcare-associated infection; MDR, multidrug-resistant; N.I., not included in the final model; OR, odds ratio. 
та в LE 4. Univariate and Multivariate Regression Analysis of the Impact of Cohort Characteristics on Mortality

\begin{tabular}{|c|c|c|c|c|c|c|c|c|c|}
\hline Variable & $\begin{array}{l}\text { Survived } \\
(\mathrm{n}=453)\end{array}$ & $\begin{array}{l}\text { Non-survived } \\
\quad(\mathrm{n}=85)\end{array}$ & $P$ & Crude OR & $(95 \% \mathrm{CI})$ & $P$ & Adj OR & $(95 \% \mathrm{CI})$ & $P$ \\
\hline Country & & & .002 & & & & & & \\
\hline Italy & $295(88.1)$ & $40(11.9)$ & & $1[$ Ref $]$ & & & $1[\operatorname{Ref}]$ & & \\
\hline Brazil & $158(77.8)$ & $45(22.2)$ & & 2.10 & $(1.32-3.35)$ & .002 & 3.58 & $(1.96-6.52)$ & $<.001$ \\
\hline Age group & & & .187 & & & & & & \\
\hline $0-28$ days & $51(75.0)$ & $17(25.0)$ & & $1[$ Ref $]$ & & & $1[\operatorname{Ref}]$ & & \\
\hline 29 days -3 months & $81(83.5)$ & $16(16.5)$ & & 0.59 & $(0.28-1.28)$ & .181 & 0.59 & $(0.25-1.38)$ & .226 \\
\hline 3 months- 2 years & $195(87.0)$ & $29(13.0)$ & & 0.45 & $(0.23-0.87)$ & .019 & 0.52 & $(0.23-1.17)$ & .112 \\
\hline $2-5$ years & $53(86.9)$ & $8(13.1)$ & & 0.45 & $(0.18-1.14)$ & .093 & 0.32 & $(0.11-0.95)$ & .039 \\
\hline$>5$ years & $73(83.0)$ & $15(17.0)$ & & 0.62 & $(0.28-1.35)$ & .225 & 0.51 & $(0.19-1.37)$ & .181 \\
\hline Male gender & $245(84.2)$ & $46(15.8)$ & .995 & 1.00 & $(0.63-1.59)$ & .995 & & & \\
\hline Underlying conditions & & & .635 & & & & & & \\
\hline No & $32(88.9)$ & $4(11.1)$ & & 1 [Ref] & & & & & \\
\hline Yes & $421(83.9)$ & $81(16.1)$ & & 1.54 & $(0.53-4.47)$ & .428 & & & \\
\hline Risk category & & & .120 & & & & & & \\
\hline Surgery & $161(85.6)$ & $27(14.4)$ & & 1 [Ref] & & & $1[\operatorname{Ref}]$ & & \\
\hline Immunodeficiency & $11(73.3)$ & $4(26.7)$ & & 2.17 & $(0.64-7.31)$ & .212 & 2.00 & $(0.52-7.77)$ & .315 \\
\hline Transplantation & $8(66.7)$ & $4(33.3)$ & & 2.99 & $(0.84-10.59)$ & .091 & 5.98 & $(1.38-25.94)$ & .017 \\
\hline Cancer & $13(81.3)$ & $3(18.8)$ & & 1.38 & $(0.37-5.15)$ & .635 & 0.96 & $(0.21-4.33)$ & .958 \\
\hline Renal failure & $10(90.9)$ & $1(9.1)$ & & 0.60 & $(0.07-4.85)$ & .629 & 0.38 & $(0.04-3.51)$ & .395 \\
\hline Prematurity & $27(71.0)$ & $11(29.0)$ & & 2.43 & $(1.07-5.47)$ & .032 & 1.70 & $(0.67-4.28)$ & .262 \\
\hline Other & $188(85.5)$ & $32(14.5)$ & & 1.01 & $(0.58-1.77)$ & .958 & 0.85 & $(0.44-1.63)$ & .616 \\
\hline Previous colonization by MDR & & & .401 & & & & & & \\
\hline No & $305(85.0)$ & $54(15.0)$ & & $1[$ Ref] & & & & & \\
\hline Yes & $113(81.9)$ & $25(18.1)$ & & 1.25 & $(0.74-2.10)$ & .402 & & & \\
\hline LOS in ICU before HAI, median (IQR), days & $24.0(11-59)$ & $24.0(13-51)$ & .912 & 1.00 & $(0.99-1.00)$ & .867 & & & \\
\hline Type of HAI & & & 0.001 & & & & & & \\
\hline Urinary tract infection & $79(92.9)$ & $6(7.1)$ & & $1[\mathrm{Ref}]$ & & & $1[\operatorname{Ref}]$ & & \\
\hline Bloodstream infection & $193(79.1)$ & $51(20.9)$ & & 3.48 & $(1.43-8.43)$ & .006 & 4.01 & $(1.50-10.61)$ & .005 \\
\hline Lower respiratory tract infection $^{\mathrm{a}}$ & $123(82.6)$ & $26(17.4)$ & & 2.78 & $(1.10-7.07)$ & .031 & 2.93 & $(1.08-8.00)$ & .036 \\
\hline Surgical site infection & $32(100.0)$ & $0(0)$ & & 1.00 & - & - & 1.00 & - & - \\
\hline Other infections & $25(92.6)$ & $2(7.4)$ & & 1.05 & $(0.20-5.55)$ & .951 & 0.88 & $(0.15-5.00)$ & .881 \\
\hline Organisms & & & .031 & & & & & & \\
\hline Gram-positive & $161(87.5)$ & $23(12.5)$ & & $1[$ Ref $]$ & & & $1[\operatorname{Ref}]$ & & \\
\hline Gram-negative & $266(83.9)$ & $51(16.1)$ & & 1.34 & $(0.79-2.28)$ & .276 & 1.51 & $(0.83-2.75)$ & .182 \\
\hline Fungi & $26(70.3)$ & $11(29.7)$ & & 2.96 & $(1.29-6.79)$ & .010 & 4.93 & $(1.88-12.90)$ & .001 \\
\hline Susceptibility & & & .060 & & & & & & \\
\hline Non-MDR & $258(86.9)$ & $39(13.1)$ & & $1[$ Ref $]$ & & & $1[\mathrm{Ref}]$ & & \\
\hline MDR & $195(80.9)$ & $46(19.1)$ & & 1.56 & $(0.98-2.49)$ & .061 & 1.85 & $(1.06-3.22)$ & .030 \\
\hline
\end{tabular}

NOTE. Data are no. (\%) unless otherwise indicated. HAI, healthcare-associated infection; ICU, intensive care unit; IQR, interquartile range; LOS, length of stay; MDR, multidrug-resistant; OR, odds ratio.

${ }^{\mathrm{a}}$ Including pneumonia. 
tract infections. ${ }^{6,16-18,20}$ These findings underline how children differ from adults in HAI distribution, emphasizing the need to target interventions focused on BSI prevention in neonates and children. ${ }^{9}$

Of the isolated pathogens, 55\% were Gram-negatives, 32\% were Gram-positives, and 7\% were fungi. This distribution is consistent with previous studies, conducted both in adults and children, showing that in ICUs most HAIs are due to Gram-negative bacteria, with Enterobacteriaceae counting for $25 \%-30 \%$ of all isolates. ${ }^{4}$

In our cohort, nearly half of the organisms grown were classified as MDR. Among Enterobacteriaceae, $45 \%$ of the isolates were positive for extended-spectrum beta-lactamase. This proportion was high compared with previous reports in hospitalized children. ${ }^{21,22}$ However, this could have been overrepresented since our definition was based only on susceptibility profile. Culture-confirmed carbapenem resistance was reported in only $2 \%$ of Enterobacteriaceae in our cohort. Infections due to carbapenem-resistant Enterobacteriaceae in adult populations have been associated with mortality rates as high as $40 \% .^{23}$ Carbapenem-resistant Enterobacteriaceae infections are still relatively uncommon in children, with prevalence being reported less than $1 \%$ and mortality rate lower compared with adults. ${ }^{24}$

In the multivariate analysis, previous colonization by an MDR pathogen was independently associated with an MDRHAI. Children have been proven to show particularly high colonization rates, representing a reservoir from which bacteria can spread. ${ }^{25}$ However, the actual mechanisms leading from colonization to infection are still debated and few surveillance data have been published so far on resistant bacteria causing invasive disease in children.

One of our aims was to evaluate the impact of different patient-level risk factors on ICU mortality. In our cohort, the 30-day case fatality rate for children with HAIs was 5.7/1,000 admissions. This proportion was comparable with previous reports in pediatric ICUs ${ }^{4}$ but lower compared with adults. ${ }^{26}$ In the multivariate analysis, factors independently associated with 30-day HAI case fatality were BSI, LRTI, and infection caused by an MDR strain. Many studies have so far failed to demonstrate a clear relationship between antimicrobial resistance and mortality. ${ }^{8,10,11,27}$ A possible explanation is that the currently used definitions for MDR bacteria may not be directly applicable in clinical care, because they do not take into account infection type, age, or risk adjustment. ${ }^{13}$

The other factor independently associated with mortality was type of infection. In our cohort, children with BSI and LRTI had a respective risk of death 4.0 and 2.9 times higher than children with other HAIs. This finding is consistent with previous studies. ${ }^{4,6,16}$

This study has some limitations. Children admitted to an ICU are a highly heterogeneous population, characterized by different medical/surgical underlying diseases. This very variable case-mix could have influenced the analysis and misrepresented the impact of different risk factors on the outcomes. We assessed risk factors with a retrospective nested case-control study design; the independent role of determinants of HAI due to MDR and of case fatality were assessed by logistic regression analysis. Other approaches, including multistate regression analysis, could be adopted to investigate multiple events associated with HAI, such as excess length of hospital stay and mortality. ${ }^{28}$ Our multicenter study was conducted in 2 countries; differences in population demographic characteristics, organization of care, and laboratory techniques for confirming HAIs and diagnosing MDR may have influenced our results. Further studies should be conducted in multiple countries to better address geographical variability. To this regard, multilevel regression analysis could be a useful tool to simultaneously investigate how population-level and individual-level factors contribute to disease outcomes. ${ }^{29}$

Education of healthcare personnel about intravascular catheter use and procedures in ICUs have proven to be effective measures to reduce the rate of central line-associated BSIs in pediatric intensive care. ${ }^{30}$ Facility data submission mandates at national and international levels have been demonstrated to improve the prevention of central line-associated BSIs and reduce the rates of central line-associated BSIs in hospitalized children. ${ }^{31}$ Targeted surveillance programs collecting neonatal and pediatric HAI/BSI data and clinical outcomes may be useful to allow global benchmarking between centers. However, the data collected for this study are just too labor intensive for routine use, especially in the setting of low- or middle-income countries. Web-based point prevalence surveys seem to be an effective tool to allow simple-to-collect data to be used to set benchmarks and monitor interventions. The Global Antimicrobial Resistance, Prescribing, and Efficacy among Neonates and Children Project, ${ }^{32}$ the repeated point prevalence surveys of HAIs and antimicrobial use in European hospitals conducted by the European Centre for Disease Prevention and Control, ${ }^{33}$ and the International Nosocomial Infection Control Consortium ${ }^{34}$ represent good examples of international initiatives aiming at reducing the burden of HAIs and their attributable mortality. The next step is to identify simple methods to monitor key HAIs and integrate these into affordable intervention programs.

\section{A C KNOWLEDGMENTS}

We thank Lucilla Ravà for her statistical support.

Financial support. None reported.

Potential conflicts of interest. All authors report no conflicts of interest relevant to this article.

Address correspondence to Laura Folgori, MD, St George's University of London, Cranmer Terrace, SW17 0RE, London, UK (laura.folgori@ gmail.com).

\section{REFERENCES}

1. Allegranzi B, Bagheri Nejad S, Combescure C, et al. Burden of endemic health-care-associated infection in developing countries: systematic review and meta-analysis. Lancet 2011;377: 228-241. 
2. Esteban E, Ferrer R, Urrea M, et al. The impact of a quality improvement intervention to reduce nosocomial infections in a PICU. Pediatr Crit Care Med 2013;14:525-532.

3. Martin-Loeches I, Diaz E, Valles J. Risks for multidrug-resistant pathogens in the ICU. Curr Opin Crit Care 2014;20:516-524.

4. Mathot F, Duke T, Daley AJ, Butcher T. Bacteremia and pneumonia in a tertiary PICU: an 11-year study. Pediatr Crit Care Med 2015;16:104-113.

5. Infectious Diseases Society of America (IDSA). The $10 \times 20$ Initiative: pursuing a global commitment to develop 10 new antibacterial drugs by 2020. Clin Infect Dis 2010;50:1081-1083.

6. McGrath EJ, Asmar BI. Nosocomial infections and multidrugresistant bacterial organisms in the pediatric intensive care unit. Indian J Pediatr 2011;78:176-184.

7. Mitt P, Metsvaht T, Adamson V, et al. Five-year prospective surveillance of nosocomial bloodstream infections in an Estonian paediatric intensive care unit. J Hosp Infect 2014;86:95-99.

8. Burnham JP, Lane MA, Kollef MH. Impact of sepsis classification and multidrug-resistance status on outcome among patients treated with appropriate therapy. Crit Care Med 2015;43: 1580-1586.

9. Lambert ML, Suetens C, Savey A, et al. Clinical outcomes of health-care-associated infections and antimicrobial resistance in patients admitted to European intensive-care units: a cohort study. Lancet Infect Dis 2011;11:30-38.

10. Lye DC, Earnest A, Ling ML, et al. The impact of multidrug resistance in healthcare-associated and nosocomial gramnegative bacteraemia on mortality and length of stay: cohort study. Clin Microbiol Infect 2012;18:502-508.

11. Patel SJ, Oliveira AP, Zhou JJ, et al. Risk factors and outcomes of infections caused by extremely drug-resistant gram-negative bacilli in patients hospitalized in intensive care units. Am J Infect Control 2014;42:626-631.

12. Horan TC, Andrus M, Dudeck MA. CDC/NHSN surveillance definition of health care-associated infection and criteria for specific types of infections in the acute care setting. Am J Infect Control 2008;36:309-332.

13. Magiorakos AP, Srinivasan A, Carey RB, et al. Multidrug-resistant, extensively drug-resistant and pandrug-resistant bacteria: an international expert proposal for interim standard definitions for acquired resistance. Clin Microbiol Infect 2012;18:268-281.

14. Monsen T, Karlsson C, Wistrom J. Spread of clones of multidrugresistant, coagulase-negative staphylococci within a university hospital. Infect Control Hosp Epidemiol 2005;26:76-80.

15. Banerjee SN, Grohskopf LA, Sinkowitz-Cochran RL, Jarvis WR. Incidence of pediatric and neonatal intensive care unit-acquired infections. Infect Control Hosp Epidemiol 2006;27:561-570.

16. Grohskopf LA, Sinkowitz-Cochran RL, Garrett DO, et al. A national point-prevalence survey of pediatric intensive care unit-acquired infections in the United States. J Pediatr 2002; 140:432-438.

17. Rutledge-Taylor K, Matlow A, Gravel D, et al. A point prevalence survey of health care-associated infections in Canadian pediatric inpatients. Am J Infect Control 2012;40:491-496.

18. Simon A, Bindl L, Kramer MH. Surveillance of nosocomial infections: prospective study in a pediatric intensive care unit. Background, patients and methods [article in German]. Klin Padiatr 2000;212:2-9.
19. Murni IK, Duke T, Kinney S, Daley AJ, Soenarto Y. Reducing hospital-acquired infections and improving the rational use of antibiotics in a developing country: an effectiveness study. Arch Dis Child 2015;100:454-459.

20. Muhlemann K, Franzini C, Aebi C, et al. Prevalence of nosocomial infections in Swiss children's hospitals. Infect Control Hosp Epidemiol 2004;25:765-771.

21. Logan LK, Braykov NP, Weinstein RA, Laxminarayan R; CDC Epicenters Prevention Program. Extended-spectrum betalactamase-producing and third-generation cephalosporin-resistant Enterobacteriaceae in children: trends in the United States, 1999-2011. J Pediatric Infect Dis Soc 2014;3:320-328.

22. Lukac PJ, Bonomo RA, Logan LK. Extended-spectrum beta-lactamase-producing Enterobacteriaceae in children: old foe, emerging threat. Clin Infect Dis 2015;60:1389-1397.

23. Gupta N, Limbago BM, Patel JB, Kallen AJ. Carbapenemresistant Enterobacteriaceae: epidemiology and prevention. Clin Infect Dis 2011;53:60-67.

24. Chiotos K, Han JH, Tamma PD. Carbapenem-resistant Enterobacteriaceae infections in children. Curr Infect Dis Rep 2016;18:2.

25. Fernandez-Reyes M, Vicente D, Gomariz M, et al. High rate of fecal carriage of extended-spectrum-beta-lactamase-producing Escherichia coli in healthy children in Gipuzkoa, northern Spain. Antimicrob Agents Chemother 2014;58:1822-1824.

26. Malacarne P, Boccalatte D, Acquarolo A, et al. Epidemiology of nosocomial infection in 125 Italian intensive care units. Minerva Anestesiol 2010;76:13-23.

27. Shime N, Kawasaki T, Saito O, et al. Incidence and risk factors for mortality in paediatric severe sepsis: results from the national paediatric intensive care registry in Japan. Intensive Care Med 2012;38:1191-1197.

28. Green N, Johnson AP, Henderson KL, et al. Quantifying the burden of hospital-acquired bloodstream infection in children in England by estimating excess length of hospital stay and mortality using a multistate analysis of linked, routinely collected data. J Pediatric Infect Dis Soc 2015;4:305-312.

29. Diez Roux AV, Aiello AE. Multilevel analysis of infectious diseases. J Infect Dis 2005;191:S25-S33.

30. O'Grady NP, Alexander M, Burns LA, et al. Guidelines for the prevention of intravascular catheter-related infections. Clin Infect Dis 2011;52:e162-e193.

31. Zachariah P, Reagan J, Furuya EY, et al. The association of state legal mandates for data submission of central line-associated bloodstream infections in neonatal intensive care units with process and outcome measures. Infect Control Hosp Epidemiol 2014;35:1133-1139.

32. Global Antimicrobial Resistance, Prescribing, and Efficacy among Neonates and Children (GARPEC). GARPEC website. http:// garpec.org/. Accessed January 24, 2016.

33. European Centre for Disease Prevention and Control (ECDC). Point prevalence survey of healthcare-associated infections and antimicrobial use in European acute care hospitals. 2011-2012. Stockholm: ECDC, 2013. http://ecdc.europa.eu/en/publications/ Publications/healthcare-associated-infections-antimicrobial-usePPS.pdf. Accessed January 24, 2016.

34. International Nosocomial Infection Control Consortium (INICC). INICC website. http://www.inicc.org/. Accessed March 3, 2016. 